\title{
The Effects of Different Type Vasodilator Agents on Radial Artery Blood Flow: A Placebo-Controlled Clinical Study
}

\author{
Ahmet Feyzi Abacilar ${ }^{1}$, Ugur Cetingok ${ }^{2}$, Mehmet Beşir Akpınar ${ }^{1}$, Omer Faruk Dogan ${ }^{*}$ \\ ${ }^{1}$ The Department of Cardiovascular Surgery, Izmir Sifa University, Bornova Education and Training Hospital, \\ Izmir, Turkey \\ ${ }^{2}$ Kudret International Hospital, Ankara, Turkey \\ ${ }^{3}$ The Department of Cardiovascular Surgery, Adana Numune Education and Training Hospital, Adana, Turkey \\ Email: *ofdogan@hacettepe.edu.tr
}

Received 6 April 2014; revised 10 May 2014; accepted 18 May 2014

Copyright (C) 2014 by authors and Scientific Research Publishing Inc.

This work is licensed under the Creative Commons Attribution International License (CC BY).

http://creativecommons.org/licenses/by/4.0/

(c) (i) Open Access

\section{Abstract}

Background: The radial artery (RA) is being used as a second arterial conduit in coronary artery bypass grafting (CABG) patients. Vasospasm during the harvesting is the most common problem, yet. Our goal of this research is to evaluate the effects of different vasodilators on RA blood flow. Material and Method: In our 250 CABG patients who were included into the study, patients were divided into five groups which have the same number of the patients. Before the harvesting of the RA, Allen test and modified Allen test were performed. In group 1, sodium nitroprusside (SNP) was administered via central line. In group 2 , nitrogliceryne was applied as a vasodilator agent. In group 3, diltiazem as a calcium channel blocker was used. In group 4, dobutamine was used with a dose of $3 \mathrm{micro} . / \mathrm{kg} / \mathrm{min}$. In the remaining patients, as a control group (CG), normal saline solution was used with the same protocol. RA length and radial artery flow, mean arterial blood pressure, central venous pressure, and heart rate were measured before and 10 minutes after drug administration. Results: No significant differences were found between the groups in respect to age, body surface area, cardiopulmonary bypass time, aortic cross clamp time. A multivariate general linear model was created and revealed the drug (specifically SNP and nitroglycerin) as a predictor to increase flow in the radial artery $(p=0.001$ and $p=0.002)$, respectively. SNP has significantly decreased mean arterial pressure when we compared to nitroglycerin $(p<0.001)$. The blood flows of RA after dobutamine and calcium channel blocker administration has not changed significantly ( $p$ > 0.05). Conclusions: Our study showed that SNP and nitroglycerin are very effective agents to provide the increasing of RA blood flow. However, statistical comparisons exhibited that intravenous SNP was a very effective vasodilating agent for RA than nitroglycerin.

*Corresponding author.

How to cite this paper:, Abacilar, A.F., et al. (2014) The Effects of Different Type Vasodilator Agents on Radial Artery Blood Flow: A Placebo-Controlled Clinical Study. World Journal of Cardiovascular Diseases, 4, 299-304. 


\section{Keywords}

\section{Radial Artery, Vasospasm, Coronary Artery Bypass Surgery}

\section{Introduction}

The radial artery is the conduit of choice as an arterial graft for coronary artery bypass grafting by many of the surgeons. However, perioperative severe conduit spasm with insufficient early graft flow has previously been reported. Thus, vasospasm can be the cause of life threatening clinical condition perioperatively and postoperatively. Many studies have suggested that during the RA harvesting, perioperative flow decrease and spasm can be seen due to manuplation and false preparations of the arterial conduits. For inhibition of the conduit spasm, the authors used different systemic or topical vasodilators such as calcium receptor inhibitors after CABG operations [1]-[3]. In recent publications, some of the authors have suggested that vasodilator use has not provided vasodilator effect. But, there is no common consensus about the routine use of vasodilator agents. Thus, our goal of this study is to evaluate the effects of different vasodilators on flow after the harvesting of RA in our 250 CABG patients.

\section{Patients and Methods}

250 patients undergoing primary CABG were included in our study. Patients were included in the study if they met the following criteria: 1) age less than 70 years, 2) ejection fraction (EF) more than 50\%, 3) no clinical evidence of congestive heart failure, 4) creatinine less than $1.2 \mathrm{mg} / 100 \mathrm{~mL}, 5$ ) no evidence of significant chronic obstructive pulmonary disease, and 6) normal liver function. Each patient's physiologic monitoring included mean arterial pressure (MAP), heart rate (HR), and central venous pressure (CVP). Anesthesia was induced with fentanyl 0.015 to $0.01 \mathrm{mg} / \mathrm{kg}$, midazolam 0.05 to $0.1 \mathrm{mg} / \mathrm{kg}$, and nurcuron $0.1 \mathrm{mg} / \mathrm{kg}$. Anesthesia was maintained with fentenyl, isoflorane, and nurcuron as needed.

\section{Surgical Procedure}

All patients were explored through a median sternotomy. Before the harvesting of the RA Allen test and modified Allen test was performed. The radial artery was dissected as a pedicle from the brachial fossa to the wrist. The artery was dissected with low voltage diathermy. Hemoclips were used to control side branches. Heparin, 300 units $/ \mathrm{kg}$, was administered intravenously before transection of the RA. The artery was then cutted and allowed to bleed freely for 30 seconds into the cab. This was defined as preoperative RA blood flow. Simultaneously, MAP, HR, and CVP were measured and recorded as preoperative measurements. After then, depending upon the assigned group, the patient received either nitroprusside 0.2 to $2 \mathrm{microgr} / \mathrm{kg} / \mathrm{min}$ for 10 minutes (Niprus; Schwarz Pharma, Mannheim, Germany), nitroglycerin a dose of 0.5 to $3 \mathrm{microgr} / \mathrm{kg} / \mathrm{min}$. for 10 minutes, dobutamine 1 to $3 \mathrm{microgr} / \mathrm{kg} / \mathrm{min}$ for 10 minutes, diltiazem $0.25 \mathrm{mg} / \mathrm{kg}$ over 2 minutes, and normal saline solution ( $0.9 \%) \mathrm{NaCl} 10 \mathrm{~mL} / \mathrm{h}$ for 10 minutes. Ten minutes after starting the drug, the blood flows of RA were measured again (postoperative flow). Hemodynamic measurements taken at the time were defined as postoperative measurement. The RA length, heart rate, MAP were recorded for each flow measurement. The time between flows 1 and 2 was recorded.

\section{Statistical Analysis}

Data are presented as mean \pm SD for continuous variables and as the number of occurrences for noncontinuous variables. Two-tailed Student's $t$ test was used to compare differences between variables at time 1 and time 2 within each drug group. One way analysis of variance (ANOVA) or $\mathrm{x}^{2}$ were used as an appropriate to compare differences between groups. The influence of different potential variables on flow ratios were studied by a multivariate general linear model. A value of P less than 0.05 was used to indicate significance.

\section{Results}

The demographic and hemodynamic data of five groups are shown in Table 1. There were no significant 
charecteristics between the groups with respect to sex ratio, body mass index, RA lenght, MAP and CVP. When we compared MAP between the groups; there was no significant differences from preoperative measurement to postoperative measurement $(\mathrm{P}>0.05)$. Thus, all groups had similar preoperative MAPs. A minimally increase in postoperative MAP was measured but not statistical significance in the dobutamine group $(\mathrm{P}=0.035)$ as we expected. There was no difference among the groups for preoperative and postoperative HR. Dobutamine caused an minimally increase in HR from preoperative to postoperative measurements $(P=0.042)$. There were no significant differences among the groups for preoperative CVP. There were no significant differences among preoperative RA flow. The significant flow increase of RA blood flow in nitroglycerin and the SNP $(\mathrm{P}<0.05)$.

A multivariate general linear model was created using drug, sex, age, body surface area, postoperative MAP/ preoperative MAP, postoperative HR/preoperative HR, postoperative CVP/preoperative CVP as predictors, and radial flow as dependent variables. Drug was the only predictor of an increase of flow in the radial artery $(\mathrm{P}=$ 0.001). Figure 1 is summarized as a graphyc the blood flows changes from the RA. Specifically, the use of sodium nitroprusside predicted an increased flow from RA $(\mathrm{P}=0.001)$. Also, nitroglycerine predicted an increase flow in the radial artery $(\mathrm{P}=0.002)$ (Table 2). In 8 patients from nitroprusside group, MAP decreased after the starting of vasodilator administration but in a few minutes it has been corrected with the volume loading. No mortality and myocardial ischemia was seen after operation. Postoperative cardiac enzyme analyses and electrocardiogarphy was recorded from all patients. There was no evidence of myocardial ischemia after operation.

\section{Discussion}

In a number of studies, the high patency rate of ITA to LIMA anastomosis has been shown. The RA in CABG patients and its association with improved survival have reported from many of the surgeons in CABG which used full arterial revascularisation in last two decades [1]-[3]. Thus, RA use is accepted as an alternative arterial bypass conduit for CABG by a number of surgeons [1]-[4]. The most common problem with the use of RA was defined as a severe spasm of the RA, which can lead to acute myocardial ischemia after operation, and

Table 1. The preoperative demographic and hemodynamic data of all groups are summarized in this table.

\begin{tabular}{|c|c|c|c|c|c|c|}
\hline Variables & Nitroglycerin & Nitroprusside & Diltiazem & Doputamine & Saline & P Value \\
\hline Mean Age (years) & $62 \pm 2.1$ & $59 \pm 1.1$ & $66 \pm 4.4$ & $61 \pm 4.4$ & $65 \pm 3.2$ & 0.89 \\
\hline Gender (M/F) & $34 / 16$ & $36 / 14$ & $37 / 13$ & $35 / 15$ & $31 / 19$ & 0.92 \\
\hline No. Of Graft & $3.4 \pm 1.2$ & $4.1 \pm 1.1$ & $3.3 \pm 1.1$ & $3.4 \pm 1.1$ & $3.1 \pm 1.3$ & 0.49 \\
\hline Mean CPB time (min.) & $69.6 \pm 3.2$ & $64.3 \pm 5.2$ & $63.4 \pm 4.1$ & $68.2 \pm 5.1$ & $65.4 \pm 2.4$ & 0.87 \\
\hline Mean AoXClamp Time (min.) & $47 \pm 5$ & $42 \pm 8$ & $41 \pm 9$ & $49 \pm 9$ & $43 \pm 6$ & 0.7 \\
\hline Mean blood pressure(mm/Hg) Preop. & $74.1 \pm 3.4$ & $68.6 \pm 1.3$ & $64.6 \pm 2.4$ & $67.8 \pm 2.5$ & $62.7 \pm 3.2$ & 0.3 \\
\hline Mean blood pressure(mm/Hg) Postop. & $62 \pm 7.4$ & $63 \pm 4.3$ & $61.4 \pm 4.2$ & $70.2 \pm 4.3$ & $61 \pm 3.9$ & 0.4 \\
\hline RA length (cm) & $18 \pm 3$ & $16 \pm 2$ & $17 \pm 1$ & $15 \pm 8$ & $16 \pm 2$ & 0.8 \\
\hline Preop HR & $65.7 \pm 6$ & $70.1 \pm 10.8$ & $68.1 \pm 4.9$ & $70.2 \pm 9.6$ & $69.6 \pm 4.1$ & 0.97 \\
\hline Postop HR & $66.8 \pm 9.9$ & $75.1 \pm 11.7$ & $76.5 \pm 5.1$ & $94.7 \pm 11$ & $70.8 \pm 8.2$ & 0.42 \\
\hline
\end{tabular}

Abbreviations: M: Male; F: Female; CPB: cardiopulmonary bypass; AoX Clamp: Aortic cross clamp; P values of each pretreatment and posttreatment pair are based on paired $t$ test. $\mathrm{P}$ values between treatment groups are based on one-way ANOVA for continuous variables and by $\mathrm{x} 2$ for sex. No any difference was found when we compared the charecteristics of the patients. The mean arterial pressures are similar preoperatively for all groups $(\mathrm{P}>0.05)$. A minimally increase in postoperative mean arterial pressure is detected in Dopamine Group $(\mathrm{P}=0.035)$. No difference among the groups when we compared the preoperative and postoperative heart rate. But, in Dobutamine group, we seen that an minimally increase in heart rate after surgery $(\mathrm{P}=0.042)$. There are no significant differences among the groups for preoperative central venous pressure and preoperative RA blood flow. The significant blood flow is detected from RA in nitroglycerin and the SNP group $(\mathrm{P}<0.05)$.

Table 2. After drug administration, the flow rates from the RA.

\begin{tabular}{cccccc}
\hline & Nitroprusside & Nitroglycerin & Diltiazem & Doputamine & Saline Sol. \\
\hline First fow & $68.1 \pm 20.7$ & $55.8 \pm 14.8$ & $49.8 \pm 11.6$ & $51.0 \pm 13.2$ & $48.0 \pm 13.2$ \\
Second flow & $116.3 \pm 17$ & $74.3 \pm 13.6$ & $53.8 \pm 13.6$ & $54.3 \pm 9.4$ \\
P value & 0.001 & 0.002 & $>0.05$ & $>0.05$ & $>0.05$ \\
\hline
\end{tabular}

MAP: mean arterial pressure. P values between treatment groups are based on one-way ANOVA. 


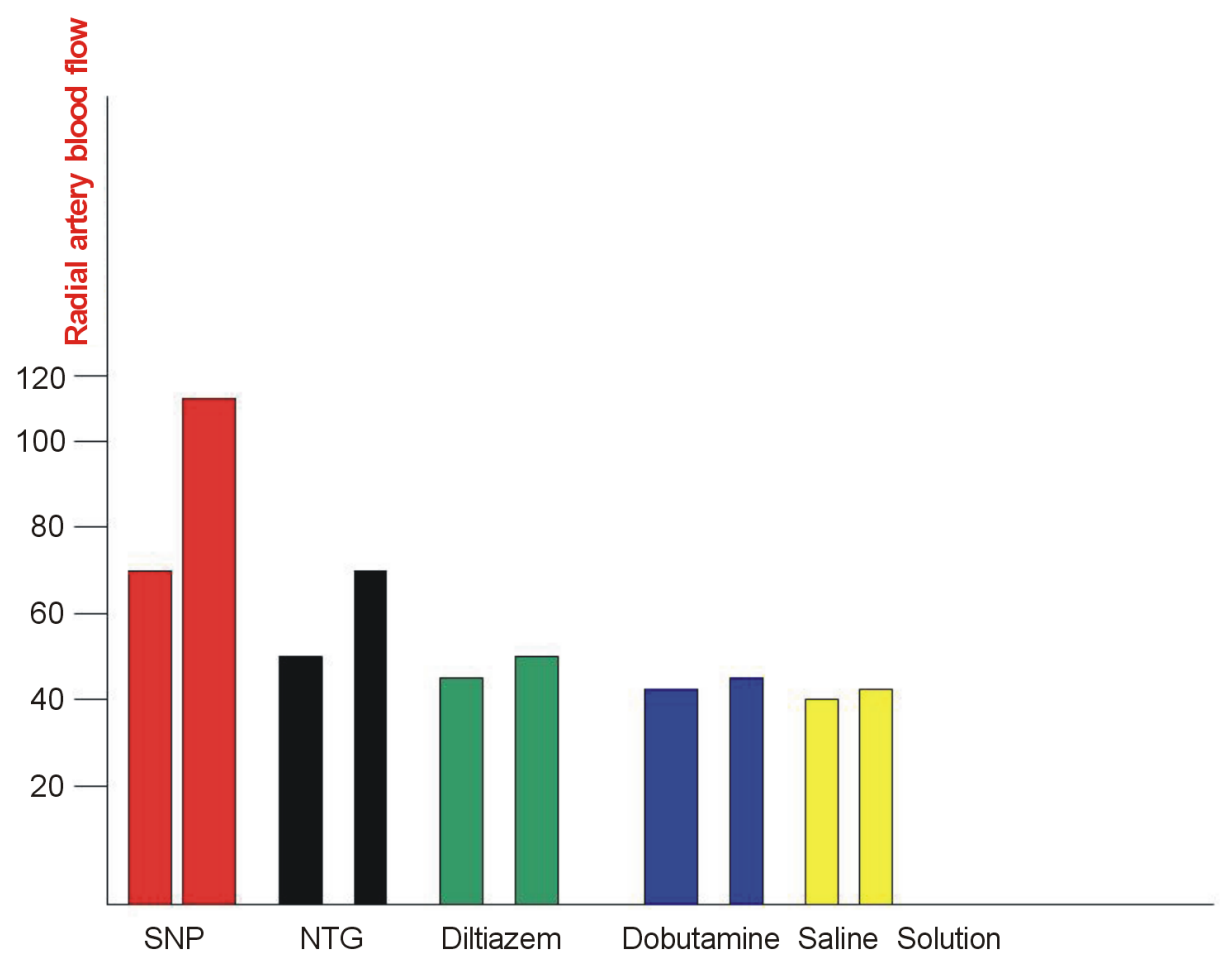

Figure 1. Shows that the change of blood flows as a graphic from the RA after the use of vasodilators and placebo.

may contribute to reduced late patency. In the previous report, Buxton et al. showed that the maximal vasoconstrictive response of the RA to noradrenalin is twice that of the IMA [4]. As we know, we see that over adrenergic responce during and after CABG. Thus, resulting from this inevitable results, vasoconstruction of arterial grafts which is life threatening condition can be seen in some CABG patients. The effect of topical and systemic vasodilators on internal thoracic artery flow in vivo has been well investigated [5]-[8]. But, the effects of systemic vasodilators on in vivo radial artery flow have not been studied well. As we known that the radial artery is midsize musculoskeletal arteries with the potential for vasoconstriction [9] [10]. Thus, the purpose of this study was to evaluate the effects of systemic vasodilators on the radial artery blood flow using different systemic vasodilators. Histologically, the radial artery has a wider lumen but thicker media with many leiomyocytes [11] and deficiencies of the internal elastic lamina [4].

Pharmacologically, the response to vasoconstriction in vitro is greater in the radial artery than the mammary artery [12] [13]. The use of verapamil and nitroglycerin solutions on the harvested radial artery has been shown to cause vasodilation [12]-[14]. Dogan et al. have investigated the quantitative efficacies of the mixed solution, which included verapamil, nitroglycerin, and papaverine, on RA using a scanning electron microscope with a 3-dimensional anaglyph technique [13]. In this study, they have showed that the described vasodilator solution with heparinized autologous blood was to be very effective and it could be used as a pretreatment agent in CABG conduits [13]. In vitro studies have shown milrinone that is able to inhibit radial artery contraction by pretreatment and to relax a precontracted radial artery [14]. When using the RA during CABG, systemic vasodilators such as calcium channel blocker during surgery are considered to be important by most of the surgeons [4] [12] [13] [14].

Acar et collegues have strongly recommended the use of calcium-channel blockers postoperatively when using the radial artery as a conduit in CABG (17). To the best of our knowledge, our study is the largest comparative study in vivo flow rates of the radial artery in CABG operations. The radial artery responds to systemic nitroprusside and nitroglycerin with an increase in flow. On the other side, nitroprusside seems to be more effective than nitroglycerin. We have previously shown this effect with mixed solution in our study involving the IMA [13], and the current findings reinforce the previous study's findings [14].

Zabeeda et al. previously reported that only nitroglycerin, as opposed to other vasodilators, had an in vivo 
effect on the radial artery flow [14]. However, in our research, we found that nitroprusside was the more effective vasodilator to increase flow in the relatively muscular radial artery. It is noteworthy that SNP increased the flow of the RA arteries at very low doses. A larger dose of nitroprusside probably would have shown a statistical increase of flow in the radial artery in the multivariate analysis. However, in our opinion, because of the systemic hypotension caused by increased doses of nitroprusside, the dose of nitroprusside should start with a minimal dose and can be increased slowly during short time administration (about 10 min.). But we see that the colloid volume overloading is protecting the patients from severe hypotensive attact. If the radial artery blood flow is weak; though, suitable systemic blood pressure, the surgeons can use nitroprusside and/or nitroglycerin intravenously with the volume overloading. From our data appears that sodium nitroprusside as nitric oxyde donor, which is known to have direct and indirect effect on smooth muscle relaxation. SNP was also superior to treatment with papaverine, glyceril trinitrate and saline. In our opinion, the effect of SNP may be continued after the operation when the patients' blood pressure is high. To provide RA graft vasospasm due to over-adrenergic responces after CPB, we propose SNP use in the ICU.

Vasoconstruction may be evoked by mechanical stimulation, as well as by various vasoconstrictor substances. In some patients who underwent treatment with SNP, the RA flow may be lower. But, if blood flow is weak when the completion of RA harvests, we should keep in mind that we can wait before the artery has made a fully spontaneous recovery from the spasm. Vasodilator treatment with the use of SNP may be helpful to provide suitable blood flow from the RA.

\section{Acknowledgements}

The authors would like to thanks to Dilek K. Dogan for the management of enteral and parenteral dietetic control of the patients with diabetes mellitus and with renal disease, who works at the Adana Numune Education and Training Hospital, as the Chief of the Department of Nutrition and Diethetics.

\section{References}

[1] Basket, R.J.F., Cafferty, F.H., Powell, S.J., Kinsman, R., et al. (2006) Total Arterial Revascularization Is Safe: Multicenter Ten-Year Analysis of 71,470. The Annals of Thoracic Surgery, 81, 1243-1248. http://dx.doi.org/10.1016/j.athoracsur.2005.12.005

[2] Wendler, O., Hennen, B., Demertzis, S., et al. (2000) Complete Arterial Revascularization in Multi-Vessel Coronary Artery Disease with 2 Conduits (Skeletonized Grafts and T Grafts). Circulation, 102, III-79-III-83. http://dx.doi.org/10.1161/01.CIR.102.suppl_3.III-79

[3] Legare, J.F., Buth, K.J., Sullivan, J.A. and Hirsch, G.M. (2004) Composite Arterial Grafts versus Conventional Grafting for Coronary Artery Bypass Grafting. The Journal of Thoracic and Cardiovascular Surgery, 127, 160-166. http://dx.doi.org/10.1016/j.jtcvs.2003.06.016

[4] Buxton, B., Fuller, J., Gaer, J., et al. (1966) The Radial Artery as a Bypass Graft. Current Opinion in Cardiology, 11, 591-598. http://dx.doi.org/10.1097/00001573-199611000-00006

[5] Arnaudov, D., Cohen, A.J., Zabeeda, D., et al. (1996) Effect of Systemic Vasodilators on İnternal Mammary Flow during Coronary Bypass Surgery. The Annals of Thoracic Surgery, 62, 1816-1819. http://dx.doi.org/10.1016/S0003-4975(96)00741-2

[6] Sasson, L., Cohen, A.J., Hauptman, E. and Schachner, A. (1995) Effect of Topical Vasodilators on İnternal Mammary Arteries. The Annals of Thoracic Surgery, 59, 494-496. http://dx.doi.org/10.1016/0003-4975(94)00896-F

[7] Cooper, G.J., Wilkinson, G.A.L. and Angelini, G.D. (1992) Overcoming Perioperative Spasm of the İnternal Mammary Artery: Which İs the Best Vasodilator? The Journal of Thoracic and Cardiovascular Surgery, 104, 465-468.

[8] Izzat, M.B., West, R.R., Ragoonanan, C. and Angelini, G.A. (1994) Effect of Systemic Vasodilators on İnternal Mammary Artery Flow. The Journal of Thoracic and Cardiovascular Surgery, 108, 82-85.

[9] Chardigny, C., Jebara, V.A., Acar, C., et al. (1993) Vasoreactivity of the Radial Artery, Comparison with the İnternal Mammary and Gastroepiploic Arteries with İmplications for Coronary Artery Surgery. Circulation, 88, 115-127.

[10] Liu, J.J., Chen, J.R. and Buxton, B.F. (1996) Unique Response of Elderly Human Arteries to Endothelin ET Receptor Agonist and Antagonist. Clinical Science, 90, 91-96.

[11] Van Son, J.A., Smedts, F., Vincents, J.G., et al. (1990) Comparative Anatomic Studies of Various Arterial Conduits for Myocardial Revascularization. The Journal of Thoracic and Cardiovascular Surgery, 99, 703-707.

[12] He, G.-W. and Yang, C.-Q. (1996) Use of Verapamil and Nitroglycerin Solution in Preparation of Radial Artery for 
Coronary Grafting. The Annals of Thoracic Surgery, 61, 610-614. http://dx.doi.org/10.1016/0003-4975(95)00920-5

[13] Dogan, O.F., Tatar, I., Duman, U., Yorgancioglu, C., Demircin, M., Aldur, M., Celik, H.H. and Boke, E. (2006) Comparison of the Pretreatment Effects of Mixed Vasodilators (3-D Solution) on Radial and İnternal Thoracic Arteries by Using a 3-Dimensional Anaglyph Electron Microscope Technique. The Heart Surgery Forum ${ }^{\circledR}$ (HSF), 9, 643-649. http://dx.doi.org/10.1532/HSF98.2006-1006

[14] Zabeeda, D., Medalion, B., Jackobshvilli, S., et al. (2001) Comparison of Systemic Vasodilators: Effects on Flow in Internal Mammary and Radial Arteries. The Annals of Thoracic Surgery, 71, 138-141.

http://dx.doi.org/10.1016/S0003-4975(00)02227-X 